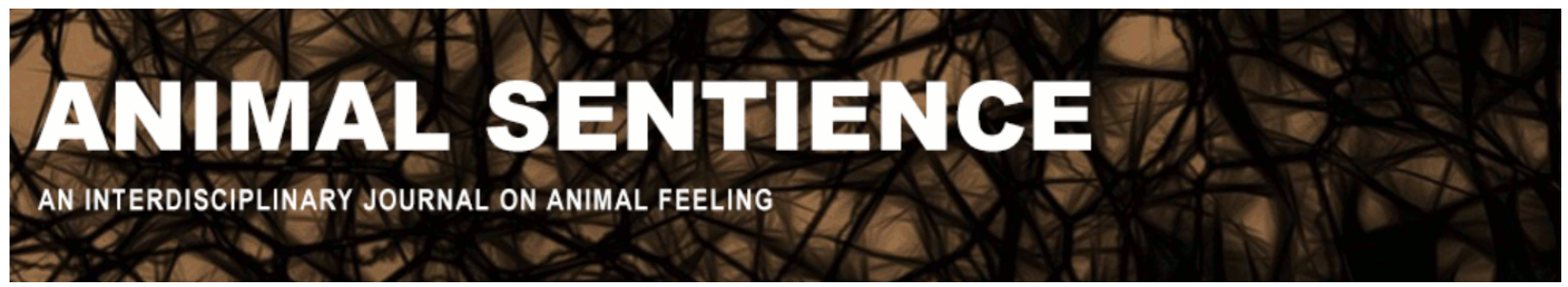

Amodio, Piero (2019) Octopus intelligence: The importance of being agnostic. Animal Sentience 26(20)

DOI: 10.51291/2377-7478.1507

Date of submission: 2019-07-19

Date of acceptance: 2019-07-25

(c)

This article has appeared in the journal Animal

Sentience, a peer-reviewed journal on animal

cognition and feeling. It has been made open access,

free for all, by WellBeing International and deposited

in the WBI Studies Repository. For more information,

please contact

wbisr-info@wellbeingintl.org.

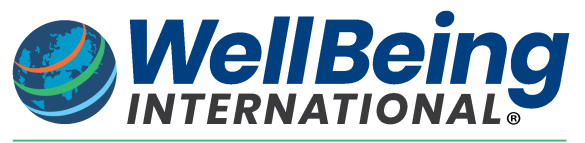

SOLUTIONS FOR PEOPLE, ANIMALS AND ENVIRONMENT 


\title{
Octopus intelligence: The importance of being agnostic
}

Commentary on Mather on Octopus Mind

\author{
Piero Amodio \\ Department of Psychology \\ University of Cambridge, UK
}

\begin{abstract}
Mather's (2019) provocative claim that octopuses have a mind hinges on the inference that their striking behavioural flexibility is evidence of "complex" cognitive abilities. I discuss alternative explanations - not to deny the possibility of complexity but to point out that current evidence does not allow us to draw firm conclusions. Only an agnostic approach will lead to the systematic investigation of octopus behaviour and ultimately, greater insights into the cognitive capacities of these fascinating creatures.
\end{abstract}

Piero Amodio, PhD candidate in Psychology at the University of Cambridge, studies the evolution of complex cognition in corvids and cephalopods. He has worked with octopuses, Eurasian jays, and orang-utans. Website

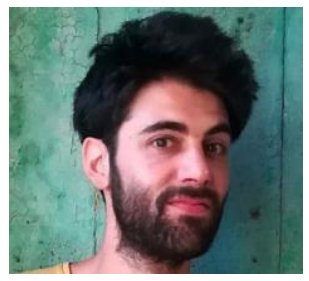

Mather (2019) provides a valuable synopsis of octopus perception, motor control and behavioural flexibility to support the conclusion that the octopus has a mind. One of the key pillars of Mather's reasoning is that the striking behavioural flexibility observed in octopuses is evidence of complex cognition, which in turn requires a mind. As pointed out by other commentators, Mather's claim that octopuses have a mind is problematic because the author does not provide a clear definition of 'mind' (Mallatt, 2019). As it currently stands, the term 'mind' is too vague to validate or disprove through scientific testing (Schnell and Vallortigara, 2019).

I will focus on an equally problematic point in Mather's approach (cf. Gutfreund, 2019): the author's interpretation of what we currently know about octopus behaviour as clear-cut evidence of complex cognition. In Mather's words: '... octopuses can perform the operations suggested by Emery and Clayton (2004) as indicative of cognitive ability in mammals and birds - flexibility, causal reasoning, prospection, and imagination'. In Figure 7, Mather provides interesting examples of octopus behaviour that supposedly demonstrate these cognitive abilities (see also Mather and Dickel, 2017). For example, the carrying of coconut shells by veined octopuses (Finn et al., 2009) is classified as an example of prospection - the ability to plan for the future. Mather also suggests that the Passing Cloud display (Packard and Sanders, 1971) and the avoidance of stinging anemones (Ross, 1971) provide evidence of causal reasoning - the ability to identify the functional relationship between a cause and its effect.

These interpretations should be considered speculative because we have limited evidence to date that alternative explanations for these behaviours can be dismissed. Moreover, 
the evidence of cognitive abilities such as future planning and causal reasoning is itself still being debated in cognitively advanced and more established model animals such as apes and corvids (Penn and Povinelli, 2007; Redshaw et al., 2017; Suddendorf and Corballis, 2007). Veined octopuses might carry coconut shells today because they can envisage that these tools can provide a benefit in the future (that they can be arranged into a den in case of a predatory attack). But this hypothesis has never been tested; so any inference about the cognitive underpinnings of this fascinating behaviour requires caution. We cannot exclude the possibility that other, simpler, mechanisms may trigger this behaviour. For example, octopuses may - in the absence of any prospective ability - carry around coconut shells only because these objects have previously become associated with a positive outcome, such as a thwarted attack by a predator or reduced stress from being covered by a protective casing (Amodio et al., 2019).

Similar arguments can be raised about the other putative examples of causal reasoning in cephalopods. Passing Cloud is a skin display characterized by a well-defined dark area that seems to 'move' directionally on the animal's body (Packard and Sanders, 1971). Cephalopods most often exhibit this to startle prey, as well as conspecifics or other animals. While it is theoretically possible that the Passing Cloud could involve causal reasoning, this interpretation is premature without careful empirical testing. We cannot yet rule out that Passing Cloud has a strong genetic component and/or simple learning mechanisms. Similarly, octopuses may develop avoidance of stinging anemones as a result of associative learning when physical interactions with the anemone have previously become associated with a negative outcome (see also Godfrey-Smith, 2019). Ross (1971) reported that octopuses: (i) behave as if they have received a 'punishment stimulus' after touching an anemone, and (ii) progressively inhibit their predatory response, selectively, toward hermit crabs that have had a stinging anemone attached to their shells.

In comparative psychology, careful testing of alternative explanations, paired with the constraint of parsimony, often favours more 'basic' mechanisms, such as associative learning, over 'higher-order' cognitive processes. This approach can foster a dichotomous view of cognition, with the risk of dismissing crucial nuances (cf. Amodio et al., 2018; Penn and Povinelli, 2007). Our understanding of non-human animals can be increased by exploring how these putatively independent systems work together (Cheke et al., 2011). There is no guarantee that favouring simpler cognitive explanations brings us closer to the truth. However, inferring sophisticated cognitive abilities without appropriate controls for simpler explanations can be even more problematic: It can fuel misleading beliefs, particularly in non-scientists, who lack the specialized background knowledge and tools to evaluate such claims critically.

Cephalopods are fascinating creatures. With their large brains, learning skills, and flexible behavioural repertoires, these molluscs are promising models for the study of complex cognition (Amodio et al., 2019; Amodio and Fiorito, 2013). But our current understanding of cephalopod cognition is still too limited to allow us to draw firm conclusions about the cognitive mechanisms underlying their behaviour. Future research may eventually support Mather's view that octopuses are capable of future planning and causal reasoning. For the time being, though, it may be wiser to adopt an optimistic agnosticism (sensu stricto Lurz et al., 2014), suspending acceptance until compelling evidence is collected. 
Acknowledgments: I am very grateful to Ljerka Ostojic and Alexandra Schnell for comments on this manuscript.

\section{References}

Amodio, P., and Fiorito, G. (2013). Observational and other types of learning in octopus. Handbook of Behavioral Neuroscience 22, 293-302. doi:10.1016/B978-0-12-415823-8.00023-X.

Amodio, P., Boeckle, M., Schnell, A. K., Ostojíc, L., Fiorito, G., and Clayton, N. S. (2019). Grow smart and die young: Why did cephalopods evolve intelligence? Trends in Ecology and Evolution 34, 45-56. doi:10.1016/j.tree.2018.10.010.

Amodio, P., Jelbert, S. A., and Clayton, N. S. (2018). The interplay between psychological predispositions and skill learning in the evolution of tool use. Current Opinion in Behavioral Science 20. doi:10.1016/j.cobeha.2018.01.002.

Cheke, L. G., Bird, C. D., and Clayton, N. S. (2011). Tool-use and instrumental learning in the Eurasian jay (Garrulus glandarius). Animal Cognition 14, 441-455. doi:10.1007/s10071-011-0379-4.

Emery, N. J., and Clayton, N. S. (2004). The mentality of crows: Convergent evolution of intelligence in corvids and apes. Science 306, 1903-1907. doi:10.1126/science.1098410.

Finn, J. K., Tregenza, T., and Norman, M. D. (2009). Defensive tool use in a coconut-carrying octopus. Current Biology 19, R1069-R1070. doi:10.1016/j.cub.2009.10.052.

Godfrey-Smith, P. (2019). Octopus experience. Animal Sentience 26(18).

Gutfreund, Y. (2019). Who needs a mind when you have thousands of fingers? Animal Sentience 26(3).

Lurz, R. W., Kanet, S., and Krachun, C. (2014). Animal mindreading: A defense of optimistic agnosticism. Mind \& Language 29, 428-454. doi:10.1111/mila.12058.

Mallatt, J. (2019). The octopus: A beautiful (but disorganized) 'mind'. Animal Sentience 26(8).

Mather, J. (2019). What is in an octopus's mind? Animal Sentience 26(1).

Mather, J. A., and Dickel, L. (2017). Cephalopod complex cognition. Current Opinion in Behavioral Science 16, 131-137. doi:10.1016/J.COBEHA.2017.06.008.

Packard, A., and Sanders, G. D. (1971). Body patterns of Octopus vulgaris and maturation of the response to disturbance. Animal Behaviour 19, 780-790. doi:10.1016/S0003-3472(71)80181-1.

Penn, D. C., and Povinelli, D. J. (2007). Causal cognition in human and nonhuman animals: A comparative, critical Review. Annual Review of Psychology 58, 97-118. doi:10.1146/annurev.psych.58.110405.085555.

Redshaw, J., Taylor, A. H., and Suddendorf, T. (2017). Flexible planning in ravens? Trends in Cognitive Science 21, 821-822. doi:10.1016/J.TICS.2017.09.001.

Ross, D. M. (1971). Protection of hermit crabs (Dardanus spp.) from octopus by commensal sea anemones (Calliactis spp.). Nature 230, 401-402. doi:10.1038/230401a0.

Schnell, A., and Vallortigara, G. (2019). "Mind" is an ill-defined concept: Consideration for future cephalopod research. Animal Sentience 26(7).

Suddendorf, T., and Corballis, M. C. (2007). The evolution of foresight: What is mental time travel, and is it unique to humans? Behavioral and Brain Sciences 30, 299-313; discussion 313-351. doi:10.1017/S0140525X07001975. 